\title{
Maintenance of pulmonary vasculature tone by blood derived from the inferior vena cava in a rabbit model of cavopulmonary shunt
}

\author{
Akio Ikai, MD \\ Mikiyasu Shirai, MD, PhD ${ }^{b}$ \\ Kazunobu Nishimura, MD, PhD ${ }^{\mathrm{a}}$ \\ Tadashi Ikeda, MD, PhD ${ }^{a}$ \\ Takayuki Kameyama, MDa \\ Koji Ueyama, MDa \\ Masashi Komeda, MD, PhDa
}

From the Department of Cardiovascular Surgery, Graduate School of Medicine, Kyoto University, ${ }^{a}$ Kyoto, and the Department of Cardiac Physiology, National Cardiovascular Center Research Institute, ${ }^{\text {b }}$ Osaka, Japan.

Received for publication July 17, 2003; revisions received Jan 13, 2004; accepted for publication Feb 13, 2004.

Address for reprints: Masashi Komeda, $\mathrm{MD}, \mathrm{PhD}$, Kyoto University, Graduate School of Medicine, Department of Cardiovascular Surgery, 54 Sakyo-ku, Kyoto, Japan, 606-8507.

J Thorac Cardiovasc Surg 2005;129: 199-206

$0022-5223 / \$ 30.00$

Copyright () 2005 by The American Association for Thoracic Surgery

doi:10.1016/j.jtcvs.2004.02.013

Introduction: After cavopulmonary shunt in which the superior vena cava is anastomosed to the right pulmonary artery, the right lung is in a unique condition without flow pulsatility and hepatic venous effluent. In a previous study, we reported that hypoxic pulmonary vasoconstriction disappeared in the pulmonary circulation after cavopulmonary shunt. In this study, however, to investigate the influence of pulsatility and hepatic venous effluent on hypoxic pulmonary vasoconstriction in the pulmonary circulation, we developed an alternative cavopulmonary shunt rabbit model that included hepatic venous effluent in the pulmonary circulation and reduced the pulsatility of the pulmonary arterial blood flow. We then observed the physiologic characteristics of the peripheral pulmonary artery after cavopulmonary shunt, specifically the disappearance of hypoxic pulmonary vasoconstriction.

Methods: Sixteen Japanese white rabbits (12-16 weeks old) were used in this study. With general anesthesia, a cavopulmonary shunt was established by anastomosing the right superior vena cava to the right pulmonary artery in an end-to-side fashion. Of the 16 rabbits for the study, the proximal right pulmonary artery was completely ligated in 5 (atresia group) and partially ligated in 6 (stenosis group). Sham operation was performed in the remaining 5 rabbits. Two weeks later, we analyzed the response of the pulmonary artery (which was divided into three categories: segmental, lobular, and acinar level artery) to hypoxia (8\% oxygen inhalation) with a specially designed video radiographic system. Morphometric analysis of the resistance pulmonary artery was done in each group after angiography.

Results: Mean pressure and pulse pressure in the right pulmonary artery were not significantly different between the atresia and stenosis groups. The mean pulmonary artery pressures in the atresia and stenosis groups were 8 and $11 \mathrm{~mm} \mathrm{Hg}$, respectively. However, the pulse pressure was less than $2 \mathrm{~mm} \mathrm{Hg}$ in both groups. The baseline internal diameter of the resistance pulmonary artery of the atresia group was significantly different from those of the stenosis and sham groups. In the atresia group, the resistance pulmonary arteries did not respond to hypoxia. In contrast, significant constriction (as assessed by percentage change of internal diameter of the resistance pulmonary arteries in the acinar and lobular level arteries) was observed in the pulmonary arteries of the sham and stenosis groups (atresia vs stenosis vs sham $0.4 \%$ vs $-19.0 \%$ vs $-18.8 \%, P=.01$ ). In our morphometric study, we observed vasodilation of the resistance pulmonary artery with a thinner medial layer in the atresia group, consistent with the result of microangiography.

Conclusion: We developed a cavopulmonary shunt rabbit model in which the inferior vena caval blood was derived from the right ventricle. Hypoxic pulmonary 
vasoconstriction was maintained in the model with the blood flow from the right ventricle. When the blood flow was not maintained, however, hypoxic pulmonary vasoconstriction disappeared. This phenomenon strongly suggests that a substance in hepatic venous effluent partially regulates the physiological pulmonary vascular function in the rabbit lung.

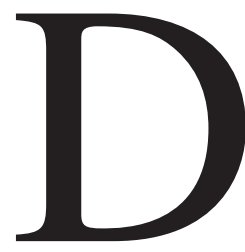

uring the last decade, bidirectional cavopulmonary shunt (CPS) has become a standard staging procedure in younger infants, resulting in improvement of the outcome of right heart bypass. ${ }^{1,2}$ However, pulmonary arteriovenous malformations have been known to have complications after CPS operations, with less improvement in outcome. ${ }^{3-5}$ Although a major symptom of pulmonary arteriovenous malformations is the deterioration of hypoxia, which has been seen with increases of right-to-left shunt in the pulmonary circulation, several echocardiographic studies have also shown an increase of intrapulmonary right-to-left shunt in more than $60 \%$ of patients after CPS despite the absence of the deterioration of hypoxia. ${ }^{6,7}$ Radionuclide studies in patients after CPS also demonstrated intrapulmonary arteriovenous shunting in all cases. ${ }^{8}$ These studies also mentioned higher incidence of pulmonary arteriovenous malformations after CPS, thus excluding hepatic venous effluence after CPS.

In our previous study, ${ }^{9}$ we confirmed abnormality of the peripheral pulmonary artery (PA) vascular tone, namely the disappearance of hypoxic pulmonary vasoconstriction (HPV) as well as the vasodilation of the peripheral PA, 2 weeks after CPS in our rabbit model. However, this model had two factors that influenced the characteristics of the pulmonary function, nonpulsatile flow and hepatic venous effluence. As a result, HPV has been recognized as an important regulatory mechanism to prevent abnormal ventilation-perfusion mismatch in the lung. This phenomenon has been observed in several mammals ${ }^{10-13}$ and has been regarded as a universal rule. Interestingly, HPV is also blunted under the condition of liver dysfunction in the rat. ${ }^{14}$

From these facts, we hypothesized that pulmonary vascular tone regulation, including HPV, is partially affected by some substance or substances in the hepatic venous effluent. To evaluate this hypothesis, we developed another rabbit model that controlled for the influence of pulsatility on the pulmonary circulation. By applying a specially designed high-resolution video radiographic system, ${ }^{15}$ we measured the internal diameters (ID) of the resistance (acinar and lobular level arteries) PAs consistent with the site of HPV and analyzed changes in basal tone and hypoxic response at each vascular level.

\section{Methods}

The institutional animal care and use committee at Kyoto University approved this protocol. All animals received humane care in compliance with the "Guide for the Care and Use of Laboratory Animals” (http://www.nap.edu/catalog/5140.html).

\section{Cavopulmonary Shunt}

A total of 16 Japanese white rabbits (12-16 weeks old and weighing 2.2-2.9 $\mathrm{kg}$ ) were subjected to a CPS. A 24-gauge intravenous catheter was placed into the marginal ear vein for intravenous access. After induction of anesthesia with intravenous induction of $25 \mathrm{mg} / \mathrm{kg}$ pentobarbital sodium, the rabbits were orally intubated and mechanically ventilated (Harvard Apparatus Constant Volume Ventilator model 683; Harvard Apparatus Co, South Natick, Mass). General anesthesia was maintained with $1.5 \%$ isoflurane. A warming pad was used to prevent hypothermia, and lactated Ringer solution was infused at the rate of $10 \mathrm{~mL} /(\mathrm{kg} \cdot \mathrm{h})$. After median sternotomy, the right superior vena cava (SVC) was extensively dissected. After $1 \mathrm{mg} / \mathrm{kg}$ heparin sodium was administered intravenously, the junction to the right atrium was ligated with 6-0 polypropylene sutures and the SVC was divided. After dissection of the right PA, the distal end of the SVC was anastomosed to the right PA in an end-to-side fashion with 8-0 polypropylene sutures.

In the atresia group $(n=5)$, the proximal side of the right PA was completely ligated. In the stenosis group $(\mathrm{n}=6)$, cuffs manufactured from sterile, medical-grade silicone tubing $(1.5 \mathrm{~mm}$ ID) were passed around the proximal right PA and fixed with 6-0 polypropylene sutures (Figure 1).

The left SVC was ligated near its drainage to the right atrium. After the procedures, the chests were closed with a mediastinal drainage tube. Extubation was performed after the rabbits were fully awakened from general anesthesia. We also performed a sham operation $(\mathrm{n}=5)$ in which the SVC and right PA were dissected and clamped for 10 minutes under heparinization as described but without constructing a CPS.

\section{Blood Gas Analysis and Pulmonary Microangiography} All rabbits were subjected to pulmonary microangiography with a specially designed high-resolution video radiographic system 2 weeks after CPS. ${ }^{15}$ General anesthesia was induced by intravenous administration of $30 \mathrm{mg} / \mathrm{kg}$ pentobarbital sodium and maintained with $2.5 \mathrm{mg} /(\mathrm{kg} \cdot \mathrm{h})$. Each rabbit was placed under spontaneous breathing condition. During this period, we also obtained arterial blood sample from the ear artery of each rabbit. Each rabbit was orally intubated and mechanically ventilated as described previously. A catheter was inserted into the right femoral artery to measure arterial pressure. Another catheter was inserted into the 

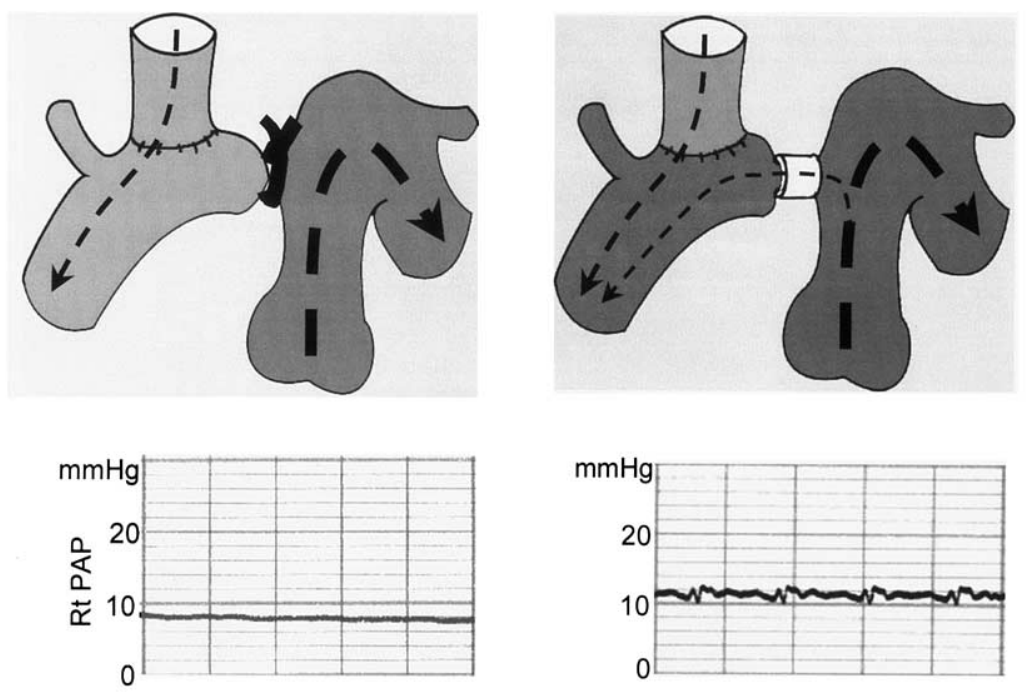

Figure 1. Model schema and representative pressure wave formation of right PA. Waveforms were recorded 2 weeks after surgery in atresia group (left) and stenosis group (right). See text for details. PAP, Pulmonary artery pressure.

right femoral vein to administer any drugs. In the stenosis group the pulse wave pressure of the right PA was $1.7 \pm 0.6 \mathrm{~mm} \mathrm{Hg}$; that in the sham group was $12.8 \pm 1.7 \mathrm{~mm} \mathrm{Hg}$. The pulse wave pressure of the atresia group was $1.0 \pm 0.5 \mathrm{~mm} \mathrm{Hg}$ (Figure 1). The right rib cages were partially excised between the 4th and 8th intercostal spaces, and the pleural cavity was opened to expose the right lower lung lobe. A catheter was introduced from the right jugular vein into the right PA through the CPS. Another catheter was introduced to the left PA through the right ventricle.

The system and experimental setup used for angiography have been described previously elsewhere. Briefly, the rabbit was placed inside a radiographic apparatus box (Hitex, Osaka, Japan) and fixed in such a manner that the exposed right lung lobe of each rabbit automatically came into contact with a plate just above the beryllium faceplate of an $\mathrm{x}$-ray-sensitive vidicon camera (Hamamatsu Photonics, Hamamatsu, Japan). During the temporary ventilation cessation at end expiration, a contrast medium $(2.7 \mathrm{~mL}$ $60 \%$ meglumine diatrizoate) was injected into the right PA at a constant speed $(1.5 \mathrm{~mL} / \mathrm{s})$, and its passage through the pulmonary vascular bed as demonstrated by the fluoroscopic image was then recorded with a videotape recorder (model PVW-2800, Sony, Tokyo, Japan) at a rate of 30 frames/s. Ventilation was temporarily arrested during each injection and recording.

\section{Measurement and Analysis of PA ID}

To determine the ID of the PA, four serial frames of angiographic images were averaged by the digital image processor (TVIP-2000; Nippon Avionics, Tokyo, Japan) and printed by the imaging hard copy unit (model UP-960; Sony). IDs of at least five randomly selected PA segments in each segmental, lobular, and acinar level PA were measured by a digitizer (model 9874A; Hewlett-Packard Company, Palo Alto, Calif). The mean value from the randomly selected ID measurements in each group was used for comparison purposes.

\section{Response of PA to Hypoxia}

We examined the change of the PA and ID of each rabbit from each group in response to hypoxia. Each rabbit was then prepared for pulmonary microangiography as described. To suppress the influence of the autonomic nerve activities, each rabbit was pretreated with $8 \mathrm{mg} / \mathrm{kg}$ hexamethonium bromide, (Sigma, St Louis, Mo) and $7 \mathrm{mg} / \mathrm{kg}$ atropine sulfate (Sigma). After the pretreatment, a baseline angiogram was recorded. The angiogram was recorded under hypoxic conditions after each rabbit was ventilated for 3 minutes with a gas mixture of $8 \%$ oxygen and $92 \%$ nitrogen. The mean value of the ID was obtained from each site. The value of the baseline and hypoxic angiogram was used to measure the percentage changes of PA and ID. After angiography, all of the rabbits were then humanely killed by an overdose of pentobarbital sodium. At this time we confirmed the patency of the stenosis of the right PA of each rabbit in the stenosis group.

\section{Histologic Evaluation of Lung}

A solution of $4 \%$ paraformaldehyde was infused through the tracheal tube through an endotracheal tube at a pressure of $20 \mathrm{~cm}$ $\mathrm{H}_{2} \mathrm{O}$. After the fixation, both lungs were then excised and immersed in $4 \%$ paraformaldehyde for about 24 hours. A block of the lower lobe, which corresponded to the site of microangiography, was cut out from each lung. These blocks were embedded in paraffin, and 4- $\mu \mathrm{m}$ slices were subjected to hematoxylin-eosin and van Gieson elastic stains. Each slice was examined by a light microscope, which was connected to a computer-assisted image analysis system (VIP-21CH Color Video Image Processor; IKEGAMI, Kawasaki, Japan). In each slice, 10 randomly selected cross-sectioned resistance arteries accompanying the end of terminal bronchiole were identified. To determine the ID of arteries, the circumference of the wavy internal elastic lamina was measured and divided by $\pi$. The medial thickness (MT) of the arteries was 
TABLE 1. Blood gas analysis 2 weeks after the operation

\begin{tabular}{llll}
\hline & \multicolumn{1}{c}{$\begin{array}{c}\text { Sham } \\
(\mathbf{n}=\mathbf{5})\end{array}$} & $\begin{array}{c}\text { Atresia } \\
(\mathbf{n}=\mathbf{5})\end{array}$ & $\begin{array}{c}\text { Stenosis } \\
(\mathbf{n}=\mathbf{6})\end{array}$ \\
\hline $\mathrm{pH}$ & $7.37 \pm 0.02$ & $7.39 \pm 0.02$ & $7.33 \pm 0.02$ \\
$\mathrm{PaO}_{2}(\mathrm{~mm} \mathrm{Hg})$ & $92.4 \pm 3.0$ & $69.3 \pm 3.5^{*}$ & $78.0 \pm 2.0^{*} \dagger$ \\
$\mathrm{PaCO}_{2}(\mathrm{~mm} \mathrm{Hg})$ & $33.1 \pm 0.9 \S$ & $39.1 \pm 1.3$ & $35.7 \pm 1.8 \dagger$
\end{tabular}

All data are mean \pm SE.

${ }^{*} P=.01$ versus sham group.

$\dagger P=.04$ versus atresia group.

$\S P=.03$ versus atresia group.

determined by the average of the MT in each quarter. The ratio between the MT and the outer diameter of the arteries was determined as follows: $\mathrm{MT}$ ratio $=2 \mathrm{MT} /(2 \mathrm{MT}+\mathrm{ID})$.

\section{Statistical Methods}

The Mann-Whitney statistical method was used to test the differences of the hemodynamic data, the blood gas values, the baseline ID in the microangiographic study, and the morphometric values among the three groups (atresia, stenosis, and sham). We then compared the hemodynamic data before and during the inhalation of hypoxic gas by Wilcoxon test. All values are expressed as mean $\pm \mathrm{SE}$.

\section{Results}

\section{Blood Gas Analysis}

To assess the development of gas-exchange abnormalities after the CPS operation, arterial blood gases were measured 2 weeks after the operation (Table 1). The $\mathrm{PaO}_{2}$ in the atresia group 2 weeks after operation was significantly decreased relative to both the stenosis and sham groups. The $\mathrm{PaCO}_{2}$ in the atresia group was significantly higher than those in the stenosis and sham groups.

\section{Hemodynamic Data}

The mean left PA pressure (PAP), mean right PAP, and mean systemic arterial pressure under basal and hypoxic conditions are summarized in Table 2. We found no significant differences in the baseline left PAP among the three groups. Under hypoxic conditions, however, the mean left PAP of all three groups increased relative to the baseline condition. The mean right PAP of the atresia group did not change at all $(8.0 \pm 0.3$ vs $8.0 \pm 0.3 \mathrm{~mm} \mathrm{Hg})$; whereas the stenosis group increased relative to the baseline condition $(10.5 \pm 0.5$ vs $13.3 \pm 1.1 \mathrm{~mm} \mathrm{Hg}, P=.03)$.

Relationship Between Vessel Sizes in the Baseline State In Figure 2, parts $A, C$, and $E$ illustrate typical arteriograms in the baseline state for the sham, atresia, and stenosis groups, respectively. In the atresia group, the lobular and acinar level arteries were thick. The results of measuring the ID of each site from the three groups are shown in Figure 3. The ID of the PA from the atresia group was increased relative to the sites of lobular and acinar level arteries from
TABLE 2. Hemodynamic changes in response to hypoxia

\begin{tabular}{|c|c|c|c|}
\hline & Left mean PAP & $\begin{array}{c}\text { Mean systemic } \\
\text { arterial pressure }\end{array}$ & Right mean PAP \\
\hline \multicolumn{4}{|c|}{ Sham $(n=5)$} \\
\hline Baseline & $16.4 \pm 1.2$ & $72 \pm 4$ & ND \\
\hline Hypoxia & $20.0 \pm 1.1^{*}$ & $70 \pm 4$ & ND \\
\hline \multicolumn{4}{|c|}{ Atresia $(n=5)$} \\
\hline Baseline & $18.8 \pm 1.3$ & $76 \pm 9$ & $8.3 \pm 0.3$ \\
\hline Hypoxia & $21.8 \pm 1.2^{*}$ & $73 \pm 8$ & $8.3 \pm 0.3$ \\
\hline \multicolumn{4}{|c|}{ Stenosis $(n=6)$} \\
\hline Baseline & $17.2 \pm 0.8$ & $69 \pm 6$ & $10.5 \pm 0.5$ \\
\hline Hypoxia & $22.0 \pm 1.3 \dagger$ & $74 \pm 8$ & $13.3 \pm 1.1 \dagger$ \\
\hline
\end{tabular}

The left PAP in the sham group is representation of whole PAP because of the continuation of bilateral PA. All measurements are in millimeters of mercury. All data are mean \pm SE. ND, Not detected.

${ }^{*} P=.04$ versus baseline.

$\dagger P=.03$ versus baseline.

the stenosis and sham groups. However, we found no significant differences in the segmental level artery from all three groups.

\section{ID Changes During Hypoxia}

In Figure 2, parts $B, D$, and $F$ show typical arteriograms with hypoxic stimulation for the sham, atresia, and stenosis groups, respectively. In Figure 4, the ID changes during hypoxia are compared among the three groups. In the sham and stenosis groups, the lobular and acinar level arteries were locally constricted. As a result of the inhalation of $8 \%$ oxygen, ID reduction did not occur in the atresia group but did so in the stenosis group. The segmental level arteries from all groups did not constrict.

\section{Morphometry}

Figure 5 shows typical resistance vessels at the end of the terminal bronchiole of the lungs of the three groups. Table 3 gives the ID and MT values of the three groups. The ID was larger in the atresia group than in the stenosis and sham groups. The MT of the resistance arteries in the atresia group was relatively thinner than in the stenosis and sham groups. These results were consistent with the microangiographic findings.

\section{Discussion}

In this study we developed two rabbit models, the atresia group and the stenosis group. In the atresia group, the pulmonary blood was supplied only from the SVC. In the stenosis group, the pulmonary blood was supplied from the SVC and the right ventricle. The flow pattern of the pulmonary circulation in the atresia group had complete steady flow, whereas the pulse pressure in the stenosis group was reduced to less than $2 \mathrm{~mm} \mathrm{Hg}$ in accordance with the stenosis site of the PA, which was between the bifurcation of the main PA and the anastomosed site of the SVC to the 

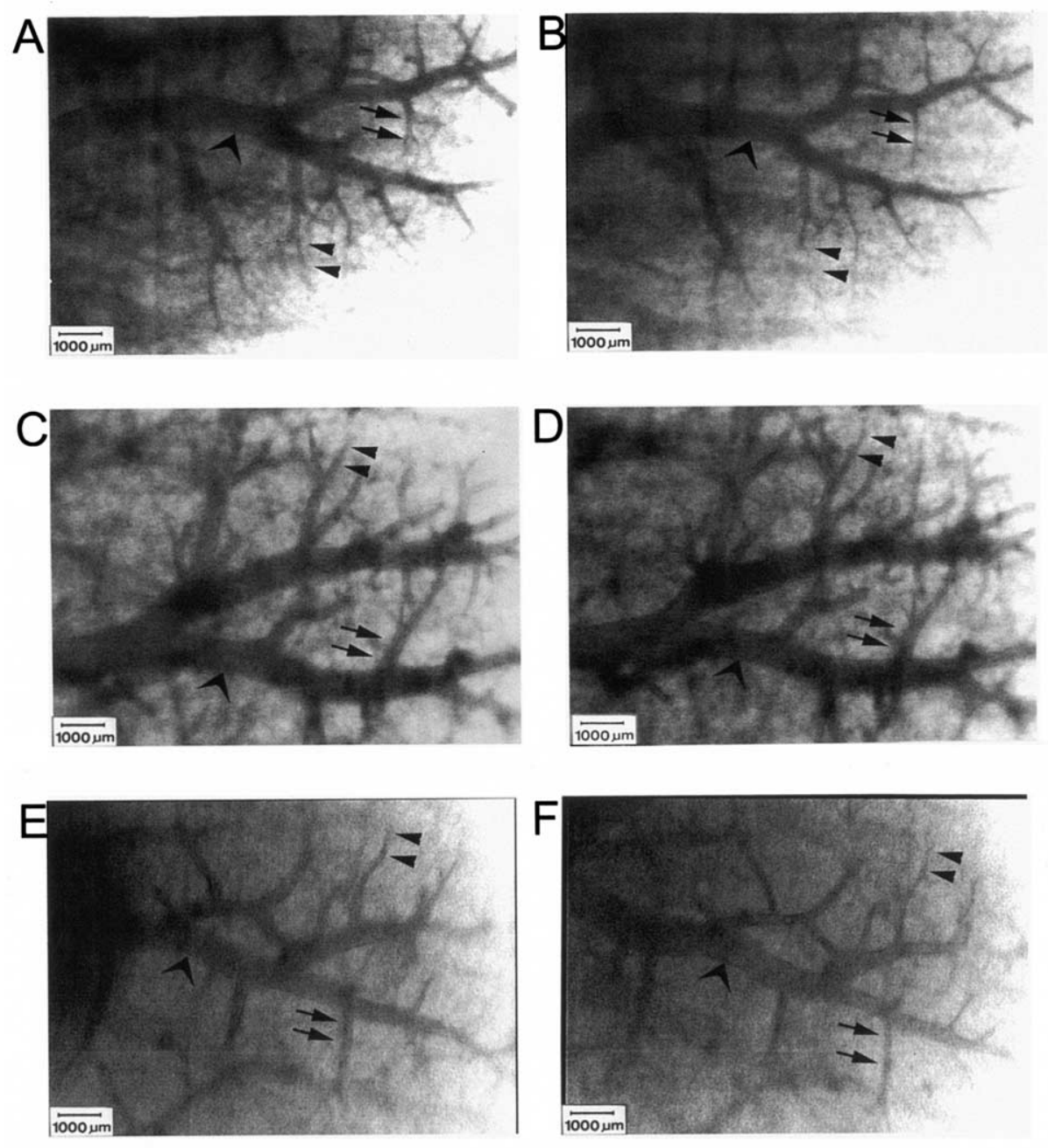

Figure 2. Typical angiograms of small PAs before and during hypoxia (8\% oxygen). Top (A and B), Sham group. Middle (C and D), Atresia group. Bottom (E and F), Stenosis group. Left (A, C, and E), Before hypoxia. Right (B, D, and E), During hypoxia. In stenosis and sham groups, lobular (arrow) and acinar (arrowhead) level arteries apparently constricted in response to hypoxia, but segmental level arteries did not (large arrowhead). In anastomosis side of atresia group, all levels of arteries did not respond at all.

right PA. Kurotobi and colleagues ${ }^{16}$ demonstrated that phenomenon in a clinical study of pulmonary endothelial function, which became abnormal after CPS when pulse pressure was subjected to $4 \mathrm{~mm} \mathrm{Hg}$ of the mean PAP. From this fact we concluded that the pulmonary pulse pressure of less than $2 \mathrm{~mm} \mathrm{Hg}$ in this model should be sufficient to induce some changes in the pulmonary circulation, as well as the steady flow in the atresia group. Therefore we expect that the functional and anatomic differences in the PA between these two groups would result from the presence of the flow from the right ventricle; specifically from flow of hepatic venous effluent.

This study showed that HPV in the atresia group disappeared, whereas it was maintained in the stenosis group and the sham groups. When the physiologic condition of the right pulmonary circulation is compared between the stenosis group and the sham group, the significant difference seen is the degree of flow pulsatility. Gregory and associates ${ }^{12,13}$ reported that HPV was maintained by a steady flow provided by a peristaltic pump in a perfusion lung model with ferrets and dogs. Ozaki and colleagues ${ }^{17}$ reported that the degree of mechanical stretch in the PA may have a profound effect on the response to hypoxia. However, they also showed that constriction response to hypoxia was observed in any degree of stretch. These findings suggest that the pulsatility of the pulmonary circulation may not be important to HPV in the rabbit lung. When we compared the atresia group with the stenosis group, the relative difference 


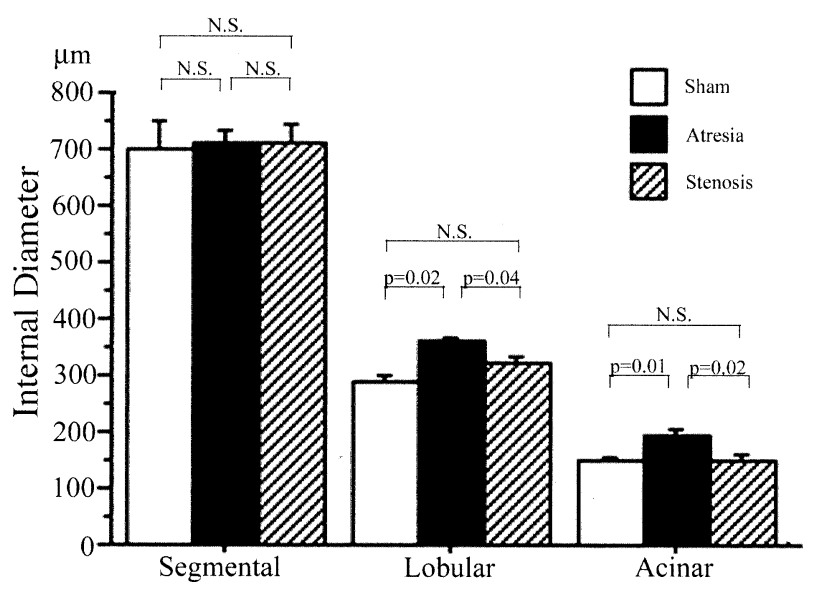

Figure 3. Comparison of ID under baseline condition among atresia (black bar, $\mathrm{n}=5$ ), sham (white bar, $\mathrm{n}=5$ ) and stenosis (striped bar, $\mathrm{n}=6$ ) groups. Baseline ID in atresia group was larger than those in other groups for lobular and acinar level arteries but not segment level arteries. N.S., Not significant.

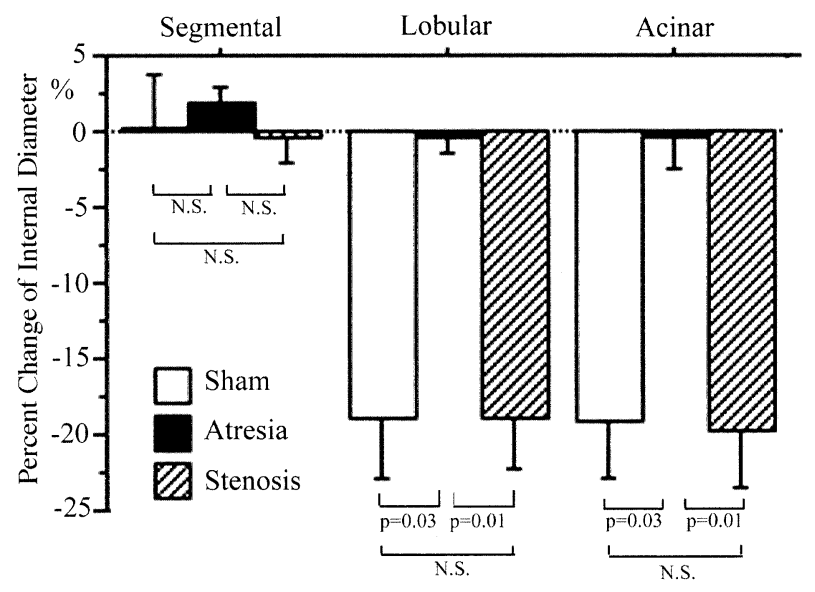

Figure 4. Comparison of ID percentage changes of PA in response to hypoxia (8\% oxygen) among atresia (black bar, $\mathbf{n}=5$ ), sham (white bar, $\mathrm{n}=5$ ) and stenosis (striped bar, $\mathrm{n}=6$ ) groups. Hypoxic ID reduction was not induced in atresia group but did occur in other groups. N.S., Not significant.

was confounded by the existence of exiguous flow pulsatility. However, the existence of the additional flow derived from the right ventricle was the main difference between the two groups. The HPV disappeared in the atresia group but was maintained in the stenosis group. However, the primary mechanism of HPV remains unclear. Because we simultaneously administered hexamethonium bromide and atropine sulfate to suppress the secondary influence of the neural reflex changes before exposure to global hypoxia, global hypoxia selectively constricted the resistance arteries. This finding is consistent with the site of locally induced hypoxic vasoconstriction. A model of hepatopulmonary syndrome was shown experimentally in a rat study. The lungs of the rats had exhibited larger diameter capillary beds and blunted HPV after the common bile duct was ligated. ${ }^{14}$ As the result of these findings, we propose that some substrates derived from the liver play a role in maintaining vasoconstrictive response to hypoxia in the pulmonary circulation. In clinical experiences, pulmonary arteriovenous malformations after CPS without hepatic venous effluent, the same condition as in our atresia group, and hepatopulmonary syndrome had significant improvement after driving the hepatic venous effluent to the pulmonary circulation. ${ }^{18,19}$ This also may support our proposed study; however, further study is needed to confirm the details of the mechanism.

In this study we demonstrated that the resistance PAs, the lobular and acinar level arteries, of the atresia group were dilated relative to those of the stenosis and sham groups. These sites are consistent with the main site of HPV. ${ }^{11}$ There have as yet been no long-term studies about the change of ID of the resistance PAs in the pulmonary circulation with the steady pulmonary flow or the exclusion of the hepatic venous effluent. In terms of the relationship between pulsatility and vasodilation, several acute studies relating shear stress of the vessel wall have shown pulsatile flow to be a more powerful stimulus to the release of nitric oxide than steady flow. ${ }^{20}$ In this study, vasodilation of the resistance PAs was induced under the condition of nonpulsatile flow. From this study, nitric oxide might not be related to this phenomenon. On the other hand, precapillary vasodilation has been shown in clinical settings under conditions of pulmonary arteriovenous malformations and CPS without hepatic venous effluent and hepatopulmonary syndrome. ${ }^{5,21} \mathrm{We}$ assume that the hepatic venous effluent, not shear stress, plays an important role in maintaining the vascular tone of the resistance PA. Malhotra and cowork$\mathrm{ers}^{22}$ reported that cavopulmonary anastomosis in an ovine model caused a reduction in the activity of angiotensinconverting enzyme and a decrease of circulating levels of angiotensin II. Not only renin-angiotensin but also several humoral factors relating vascular tone regulation were metabolized in the pulmonary vascular beds (eg, endothelin, eicosanoid, and bradykinin). Some of these are also recognized as modulating HPV. ${ }^{23,24}$ Further study is required to determine the particular factors that regulate pulmonary vascular tone. However, if some specific factor regulating pulmonary vascular tone that is derived from the liver theoretically exists, it should have a very short half-life or it would be metabolized completely by its second passage into the pulmonary circulation. This metabolic process may be due to the disappearance of HPV, or it may be that the vasodilation of the PA only occurred in the atresia group.

The $\mathrm{PaO}_{2}$ values in the atresia and stenosis groups were significantly lower than that in the sham group. The follow- 

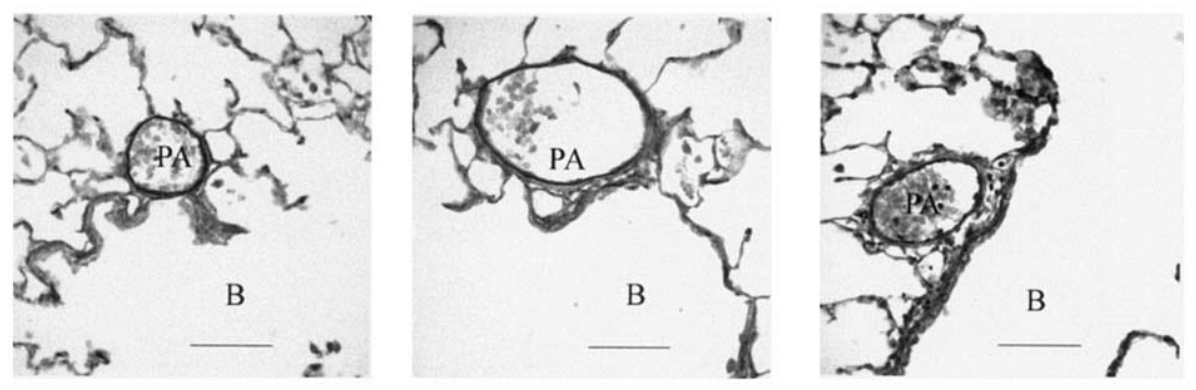

Figure 5. Typical light microscopic photography of small PAs in end of terminal bronchiole 2 weeks after operation. Left, Section representing sham group. Center, Section representing atresia group. Right, Section representing stenosis group. PA of atresia group was dilated larger than in other two groups. $B$, Bronchiole. Horizontal bar represents $100 \mu \mathrm{m}$ in length.

ing factors may explain this result. Basically, a rabbit has four lobes in the right lung and a lobe in the left lung. The volume of the right lung is larger than that of the left lung. The rabbits in the atresia and stenosis group may have had tremendous distribution mismatch of pulmonary blood flow and pulmonary vascular bed as a result of the procedure. This may have been one of the causes of low $\mathrm{PaO}_{2}$ relative to control animals. The difference in $\mathrm{PaO}_{2}$ between the atresia group and stenosis group may be explained following factors. One of the underlying factors is the abnormal dilatation of the peripheral resistance arteries. It has been shown that the nonpulsatile passive blood without hepatic venous effluent returned to the lungs after CPS has caused more dominant flow into the lower lobes, causing mismatch of ventilation to perfusion. ${ }^{3}$ The abnormal vasodilatation may further enhance this mismatching. In a long-term goat model with nonpulsatile pulmonary perfusion by centrifugal pump derived from the right atrium and ventricle, however, blood distribution on the pulmonary circulation and the blood gas values were not changed. ${ }^{25}$ As a result of these findings, the lack of hepatic venous blood may contribute more to the maldistribution of pulmonary blood flow than does flow pulsatility alone. Another possible factor is the lack of HPV in the peripheral resistance arteries after CPS, which may aggravate ventilation or perfusion mismatching. Furthermore, the flow distribution of each lung in each group should be different in this study. This speculation may be partially related to ventilation or perfusion mismatching.

There are some limitations in this experimental study. The aim of this study was to confirm the physiologic characteristics of the PA after CPS without pulsatile flow and with hepatic venous effluent. In this sense, however, this model was imperfect because pulse wave pressures in the stenosis group were not eliminated completely. Ideally, it should have been established that the inferior vena cava was anastomosed to the right PA directly to get steady flow including hepatic venous effluent. Although we tried to
TABLE 3. Morphometric study

\begin{tabular}{lccc}
\hline & $\begin{array}{c}\text { Sham } \\
(\mathbf{n}=\mathbf{5})\end{array}$ & $\begin{array}{c}\text { Atresia } \\
(\mathbf{n}=\mathbf{5})\end{array}$ & $\begin{array}{c}\text { Stenosis } \\
(\mathbf{n}=\mathbf{6})\end{array}$ \\
\hline ID $(\mu \mathrm{m})$ & $104 \pm 2$ & $162 \pm 14^{*}$ & $108 \pm 2$ \\
MT $(\mu \mathrm{m})$ & $6.1 \pm 0.5$ & $4.8 \pm 0.3 \dagger$ & $6.0 \pm 0.3$ \\
\hline
\end{tabular}

All data are mean \pm SE.

${ }^{*} P<.05$ versus sham and stenosis groups.

$\dagger P=.04$ versus sham group and $P=.03$ versus stenosis group.

develop this model, we failed because of the relatively small animal we used for the study. In terms of histologic study, the lungs were not perfusion-fixed at a standard pressure. Therefore it was difficult to compare differences in the PA wall thickness and muscular development between the study animals.

In conclusion, we developed a small CPS rabbit model with and without pulmonary blood forward blood flow from the right ventricle. HPV was maintained in the model with forward blood flow from the right ventricle, but without forward blood flow it disappeared. This phenomenon strongly suggests that a substance derived from hepatic venous effluent regulates normal physiologic pulmonary function.

\section{References}

1. Bridges ND, Jonas RA, Mayer JE, Flanagan MF, Keane JF, Castaneda AR. Bidirectional cavopulmonary anastomosis as interim palliation for high-risk Fontan candidates. Early results. Circulation. 1990; 82(Suppl):IV170-6.

2. Reddy VM, Liddicoat JR, Hanley FL. Primary bidirectional superior cavopulmonary shunt in infants between 1 and 4 months of age. Ann Thorac Surg. 1995;59:1120-6.

3. Cloutier A, Ash JM, Smallhorn JF, Williams WG, Trusler GA, Rowe $\mathrm{RD}$, et al. Abnormal distribution of pulmonary blood flow after the Glenn shunt or Fontan procedure: risk of development of arteriovenous fistulae. Circulation. 1985;72:471-9.

4. Trusler GA, Williams WG, Cohen AJ, Rabinovitch M, Moes CA, Smallhorn JF, et al. William Glenn lecture. The cavopulmonary shunt. Evolution of a concept. Circulation. 1990;82(Suppl):IV131-8.

5. Srivastava D, Preminger T, Lock JE, Mandell V, Keane JF, Mayer JE 
$\mathrm{Jr}$, et al. Hepatic venous blood and the development of pulmonary arteriovenous malformations in congenital heart disease. Circulation. 1995;92:1217-22.

6. Chang RK, Alejos JC, Atkinson D, Jensen R, Drant S, Galindo A, et al. Bubble contrast echocardiography in detecting pulmonary arteriovenous malformation in children with univentricular heart after cavopulmonary anastomosis. J Am Coll Cardiol. 1999;33:2052-8.

7. Bernstein HS, Ursell PC, Brook MM, Hanley FC, Silverman NH, Bristow J. Fulminant development of pulmonary arteriovenous fistulas in an infant after total cavopulmonary shunt. Pediatr Cardiol. 1996; 17:46-50.

8. Vettukattil JJ, Slavik Z, Lamb RK, Monro JL, Keeton BR, Tsang VT, et al. Intrapulmonary arteriovenous shunting may be a universal phenomenon in patients with the superior cavopulmonary anastomosis: a radionuclide study. Heart. 2000;83:425-8.

9. Ikai A, Shirai M, Nishimura K, Ikeda T, Kameyama T, Ueyama K, et al. Hypoxic pulmonary vasoconstriction disappears in a rabbit model of cavopulmonary anastomosis. J Thorac Cardiovasc Surg. 2004;127: 1450-7.

10. Von Euler US, Liljestrand G. Observation on the pulmonary arterial blood pressure in the cat. Acta Physiol Scand. 1946;12:301-20.

11. Shirai M, Sada K, Ninomiya I. Effect of regional alveolar hypoxia and hypercapnea on small vessels in cats. J Appl Physiol. 1986;61:440-48.

12. Gregory TJ, Ellsworth ML, Newell JC. Hypoxic pulmonary vasoconstriction during steady and pulsatile flow in ferrets. J Appl Physiol. 1984;57:205-12.

13. Gregory TJ, Newell JC, Hakin MG, Levitzky MG, Sedransk N. Attenuation of hypoxic vasoconstriction by pulsatile flow in dog lungs. J Appl Physiol. 1982;53:1583-8.

14. Chang S, Ohara N. Pulmonary circulatory dysfunction in rats with biliary cirrhosis: an animal model of the hepatopulmonary syndrome. Am Rev Respir Dis. 1992;148:798-805.

15. Sada K, Shirai M, Ninomiya I. X-ray TV system for measuring microcirculation in small pulmonary vessels. J Appl Physiol. 1985;59: 1013-8.

16. Kurotobi S, Sano T, Kogaki S, Matdushita T, Miwatani T, Takeuchi $\mathrm{M}$, et al. Bidirectional cavopulmonary shunt with right ventricular outflow patency: the impact of pulsatility on pulmonary endothelial function. J Thorac Cardiovasc Surg. 2001;121:1161-8.

17. Ozaki M, Marshall C, Amaki Y, Marshall BE. Role of wall tension in hypoxic responses of isolated rat pulmonary arteries. Am J Physiol. 1998;275:L1069-77.

18. Knight WB, Mee RB. A cure for pulmonary arteriovenous fistulas? Ann Thorac Surg. 1995;59:999-1001.

19. Laberge JM, Brandt ML, Lebecque P, Moulin D, Veykemans F, Paradis K, et al. Reversal of cirrhosis related pulmonary shunting in two children by orthotopic liver transplantation. Transplantation. 1992;53:1135-8

20. Hakim TS. Flow-induced release of EDRF in the pulmonary vasculature: site of release and action. Am J Physiol. 1994;267(1 Pt 2): H363-9.

21. Lange PA, Stroll JK. The hepatopulmonary syndrome. Ann Intern Med. 1995;122:521-9.

22. Malhotra SP, Riemer RK, Thelitz S, Ho YP, Hanley FL, Reddy VM. Superior cavopulmonary anastomosis suppresses the activity and expression of pulmonary angiotensin-converting enzyme. $J$ Thorac Cardiovasc Surg. 2001;122:464-9.

23. Liu Q, Sham JS, Shimoda LA, Sylvester JT. Hypoxic constriction of porcine distal pulmonary arteries: endothelium and endothelin dependence. Am J Physiol Lung Cell Mol Physiol. 2001;280:L856-65.

24. Madden JA, Vadula MS, Kurup VP. Effects of hypoxia and other vasoactive agents on pulmonary and cerebral artery smooth muscle cells. Am J Physiol. 1992;263:L384-93.

25. Sakaki M, Taenaka Y, Tatsumi E, Nakatani T, Takano H. Influences of nonpulsatile pulmonary flow on pulmonary function. Evaluation in a chronic animal model. J Thorac Cardiovasc Surg. 1994;108:495-502. 